\title{
Microwave diodes with contact metallization systems based on silicides, nitrides and borides of refractory metals
}

\author{
N.S. Boltovets, V.V. Basanets, V.N. Ivanov, V.A. Krivutsa \\ State Scientific \& Research Institute "Orion", 8a Eugene Pottier St., Kyiv, 03057, Ukraine \\ Tel.: (380-44) 456-05-48; E-mail: bms@i.kiev.ua
}

\author{
A.E. Belyaev, R.V. Konakova, V.G. Lyapin, V.V. Milenin, E.A. Soloviev, E.F. Venger, \\ D.I. Voitsikhovskyi \\ Institute of Semiconductor Physics, NAS Ukraine, 45 Prospect Nauki, Kyiv, 03028, Ukraine \\ Tel.: (380-44) 265-61-82; Fax: (380-44)265-83-42; E-mail: konakova@eee.semicond.kiev.ua
}

\author{
V.V. Kholevchuk, V.F. Mitin \\ Microsensor Ltd., Kyiv, Ukraine
}

\begin{abstract}
We investigated the parameters of silicon and gallium arsenide microwave diodes intended for different functions. Their heat-resistant contacts were made on the base of interstitial phases. A unified technological route is proposed to produce microdiodes with bulk contacts. Tests of these silicon and gallium arsenide microwave diodes in forced modes demonstrated their high heat stability.
\end{abstract}

Keywords: microwave diodes, diode temperature sensors, metallization, silicides, nitrides, borides, refractory metals, reliability.

Paper received 03.05.00; revised manuscript received 22.06.00; accepted for publication 30.06.00.

\section{Introduction}

We have developed the diodes design and manufacturing technology, as well as investigated the degradation of their parameters. Both the diode structure designs and diode manufacturing procedures were developed so as to (i) block the unwanted mass transport and (ii) provide a secure connection of the diode chips contact systems to both the semiconductor mesa and package elements. The chips were mounted in the commercial metal-corundum packages. The diodes of the following types were developed and studied: IMPATT diodes, switching diodes, varactor diodes, Gunn diodes, microwave oscillating diodes based on the resonant tunneling structure and silicon diode temperature sensors.

Concurrently we investigated the most probable mechanisms for the diode degradation during long-term operation in the extreme modes. It is known that one of the principal mechanisms of the catastrophic failures for microwave oscillating diodes (IMPATT and Gunn diodes) is the mass transport of heat sink materials $(\mathrm{Au}, \mathrm{Cu})$ through the barrier layer to diode active areas and the active areas penetration $[1,2]$. This penetration is due to formation of multicomponent eutectic alloys whose melting temperatures lie in the range from 300 to $400{ }^{\circ} \mathrm{C}$ [3]. Another important mechanism for catastrophic failures may be the adhesion break in the contact system or at metal-semiconductor interface. This may result in the contact break or lead to the increase of both conductivity and heat conductivity in the case of partial break of adhesion.

\section{IMPATT diodes}

We have developed the design and manufacturing technology for a diode chip made as a reversed $p^{+}-p-n-n^{+}-$ type mesa on the integrated heat sink. During diode operation the temperature of the mesa active area $(n-p)$ may be as high as $200-250^{\circ} \mathrm{C}$, so the requirements to both the contact system reliability and technology of the diode chip mounting in the package are very severe [4]. Bearing this in mind, we formed the barrier layers ( $\mathrm{TiN}, \mathrm{TiB}_{2}$ ), 100 to $200 \mathrm{~nm}$ thick, between the integrated heat sink and $p^{+}$region. The minimum values of the transient resistance and heat resistance at the maximum adhesion 


\section{N.S. Boltovets et al.: Microwave diodes with contact metallization systems ...}

were provided by formation of a thin (from 30 to $50 \mathrm{~nm}$ ) palladium (or titanium) silicide layer at the contact system-semiconductor interface. We have studied the diodes with the following contact system metallizations: $\mathrm{Pd}_{2} \mathrm{Si}$ TiN-Au, Ti-TiB $2-\mathrm{Mo}-\mathrm{Au}$ and $\mathrm{Pd}_{2} \mathrm{Si}-\mathrm{Ti}-\mathrm{Pd}-\mathrm{Au}$. The TiN barrier layers were formed by thermal ion reactive synthesis, while those of $\mathrm{TiB}_{2}$ were obtained by magnetron sputtering of the targets of stoichiometric composition.

A technological route has been developed to realize a chip as a reversed $p^{+}-p-n-n^{+}$-type mesa on the integrated heat sink (see Fig. 1). The silicon epitaxial structures of the $p-n-n^{+}$-type were used as the starting material. The mesa design was as follows: a silicon disc 8-12 $\mu \mathrm{m}$ thick and 25 to 40 (100 to 200) $\mu \mathrm{m}$ in diameter for the continuous (pulse) operation diodes. The integrated heat sink was a copper disc (coated with gold) $80-100 \mu \mathrm{m}$ thick and $500 \mu \mathrm{m}$ in diameter. The upper contact (to the $n^{+}$region) was a gold disc 3-5 $\mu \mathrm{m}$ thick. The IMPATT diode design is shown in Fig. 2.

Thin (30-50 nm) palladium (titanium) silicide layers were formed at the contact system-semiconductor interfaces to provide the minimum values for transient resistance and heat resistance at the highest adhesion. To connect the mesa contact systems to the elements of the metal- corundum package the low-temperature thermal diffusion welding and thermal compression welding were used. The diode chips were mounted in the commercial metalcorundum packages. The diode manufacturing technology provides a possibility of undercutting the mesa in the package to the needed diameter value. The diode parameters are given in Tables 1 and 2.

When oscillating in the continuous mode, the diodes provided the microwave power of 200-300 (20-50) $\mathrm{mW}$ in the 50 to 60 (90 to 140$) \mathrm{GHz}$ frequency range, the $p-n$ junction temperature being about $200{ }^{\circ} \mathrm{C}$. In the pulse operation mode the diodes provided the microwave power of $10-20 \mathrm{~W}$ in the 33 to $99 \mathrm{GHz}$ frequency range. The adhesion breaking strength was $400-600 \mathrm{kgf} / \mathrm{cm}^{2}$. The typical values of the diode heat resistance were below $60{ }^{\circ} \mathrm{C} / \mathrm{W}$, the mesa diameter being $35-40 \mu \mathrm{m}$. The above values indicate at good diode characteristics.

We have studied the stability of diode parameters when operating in the forced mode at the $p$ - $n$ junction temperature of $335^{\circ} \mathrm{C}$, as well as their radiation tolerance to the ${ }^{60} \mathrm{Co} \gamma$-radiation (total doses from $10^{5}$ up to $10^{9} \mathrm{R}$ ). The diodes demonstrated a rather high stability of their parameters during the forced operation for over 1000 hours and after g-irradiation up to a dose of $2 \times 10^{7} \mathrm{R}$.

Table 1. Oscillating and amplifying IMPATT diodes (continuous operation mode)

( $U_{R}$ - reverse voltage, $U_{B}$ - breakdown voltage).

\begin{tabular}{lccccc}
\hline \hline Operation frequency, $\mathrm{GHz}$ & $33-37$ & $58-62$ & $70-77$ & $92-96$ & $120-140$ \\
\hline $\begin{array}{l}\text { Minimum continuous power at the } \\
\text { operation frequency, } \mathrm{mW}\end{array}$ & $200-300$ & $150-200$ & $100-200$ & $70-100$ & $20-50$ \\
\hline Breakdown voltage, $\mathrm{V}$ & & & & & \\
\hline Operation current, $\mathrm{mA}$ & $34-40$ & $20-26$ & $20-21$ & $13-16$ & $10-12$ \\
\hline Operation voltage, $\mathrm{V}, \mathrm{no}$ more than & $U_{B}+10$ & $U_{B}+8$ & $U_{B}+4$ & $U_{B}+4$ & $U_{B}+4$ \\
\hline Diode capacitance $\left(U_{R}=0\right), \mathrm{pF}$ & $1.3-2.0$ & $0.8-1.2$ & $0.7-0.8$ & $0.7-0.9$ & $0.6-0.8$ \\
\hline Package capacity, $\mathrm{pF}$ & 0.2 & 0.16 & 0.16 & 0.12 & 0.08 \\
\hline Corundum bush sizes, $\mathrm{mm}$ & $1.2 \times 0.7 \times 0.4$ & $0.9 \times 0.55 \times 0.3$ & $0.9 \times 0.55 \times 0.3$ & $0.5 \times 0.2 \times 0.15$ & $0.4 \times 0.2 \times 0.15$ \\
& & & & $0.8 \times 0.4 \times 0.2$ & \\
\hline \hline
\end{tabular}

Table 2. Oscillating and amplifying IMPATT diodes (pulse operation mode)

( $U_{R}$ - reverse voltage).

\begin{tabular}{lcccc}
\hline \hline Operation frequency, $\mathrm{GHz}$ & $33-37$ & $58-62$ & $92-96$ & $120-140$ \\
\hline Minimum power, $\mathrm{W}$ & $10-20$ & 10 & 10 & 5 \\
\hline Breakdown voltage, $\mathrm{V}$ & $34-40$ & $20-26$ & $13-16$ & $10-12$ \\
\hline Operation current, $\mathrm{A}$ & $8-15$ & $10-15$ & $10-18$ & $10-18$ \\
\hline Diode capacitance $\left(U_{R}=0\right), \mathrm{pF}$ & $10-26$ & $8-12$ & $6-8$ & $6-8$ \\
\hline Package capacity, $\mathrm{pF}$ & 0.2 & 0.16 & 0.12 & 0.08 \\
\hline Corundum bush sizes, $\mathrm{mm}$ & $1.2 \times 0.7 \times 0.4$ & $0.9 \times 0.55 \times 0.3$ & $0.5 \times 0.2 \times 0.15$ & $0.4 \times 0.2 \times 0.15$ \\
& & & $0.8 \times 0.4 \times 0.2$ & \\
\hline
\end{tabular}


N.S. Boltovets et al.: Microwave diodes with contact metallization systems ...

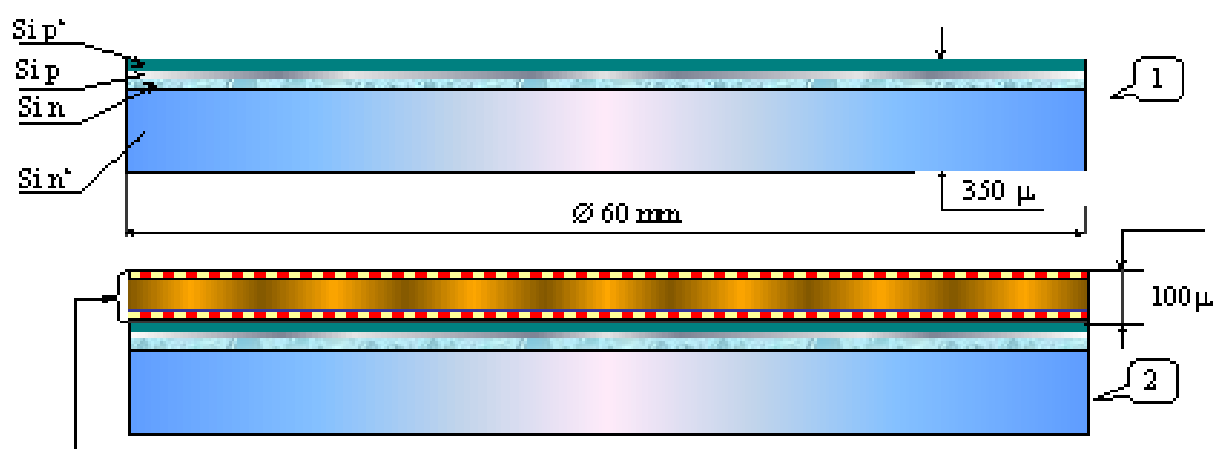

$\mathrm{Pd}_{2} \mathrm{Si}(0.1 \mu)-\mathrm{TiN}(0.1 \mu)-\mathrm{Ti}(0.05 \mu)-\mathrm{Au}(3 \mu)-\mathrm{Ki}(1 \mu)-\mathrm{Cu}(80 \mu)-\mathrm{Ki}(1 \mu)-\mathrm{Au}(3 \mu)$
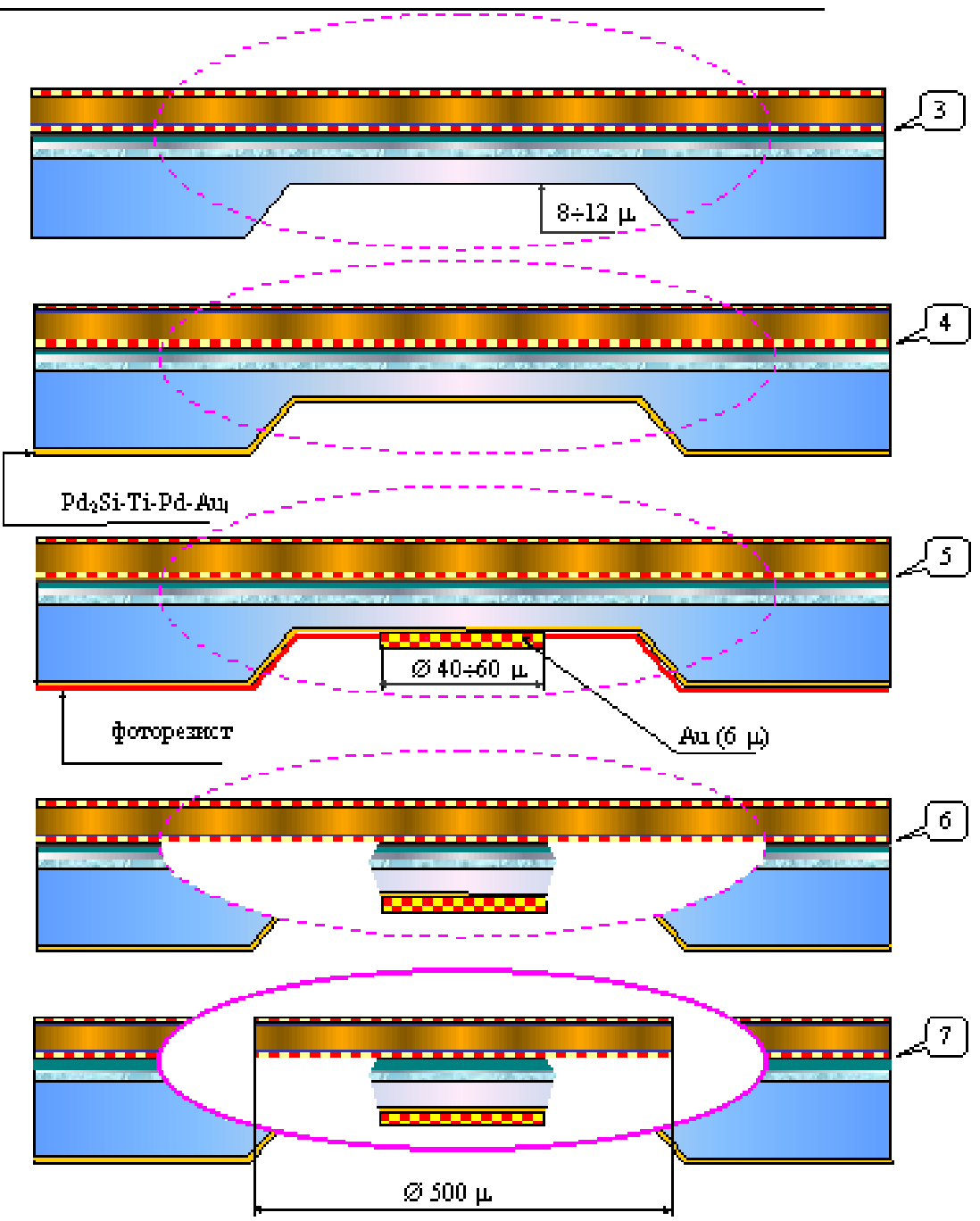

Fig. 1. A diagram of technological route for IMPATT diodes manufacturing: 1 - silicon multilayer $p^{+}-p-n-n^{+}$-structure; 2 - formation of contact system (including integrated heat sink); 3 -formation of silicon membrane (8-12 $\mu \mathrm{m}$ thick) on the integrated heat sink; 4 - ohmic contact deposition onto the membrane $n^{+}$-region; 5 - formation of mesa bonding area; 6 - mesa etching; 7 - formation of diode chip (reverse mesa on the integrated heat sink). 


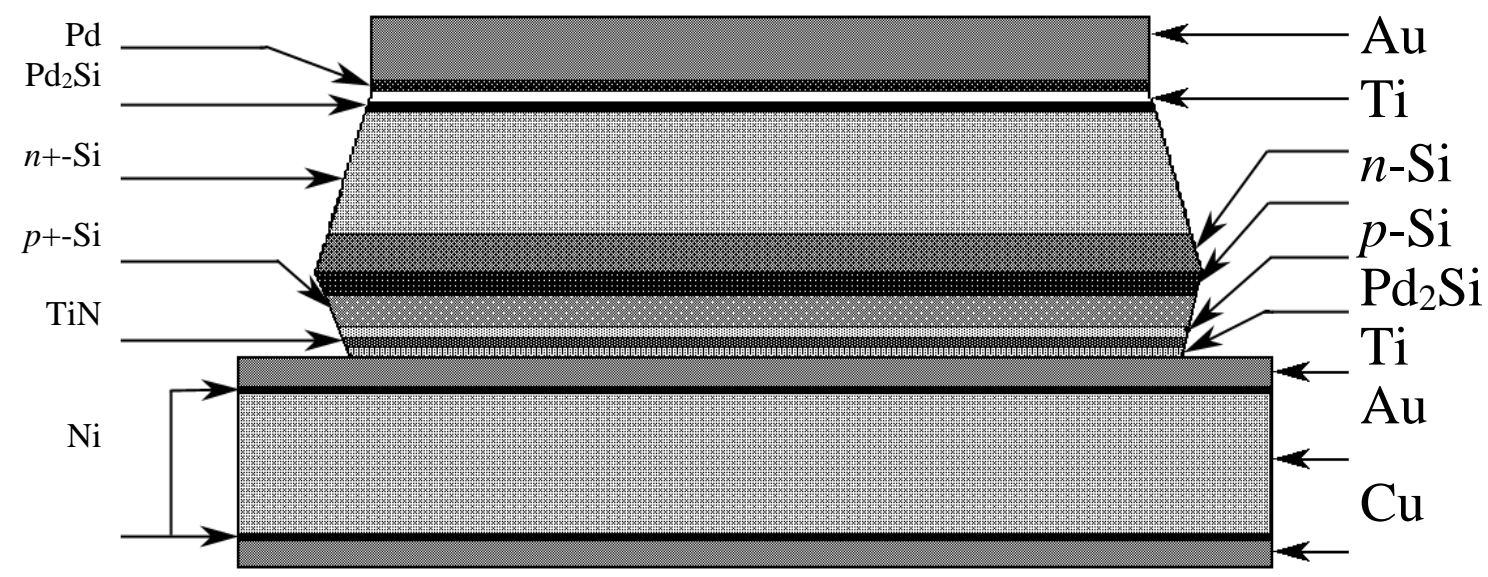

$\mathrm{Au}$

Fig. 2. The IMPATT diode chip design.

\section{Fast-operating switching diodes}

A chip of a switching diode was a reversed $p^{+}-n-n^{+}$-type mesa on the integrated heat sink. The silicon epitaxial structures of the $n-n^{+}$-type were used as the starting material. The mesa active $(n)$ area thickness was 2 to $5 \mu \mathrm{m}$. We have studied the diodes with the following contact system metallizations: $\mathrm{Pd}_{2} \mathrm{Si}-\mathrm{Ti}-\mathrm{Au}$ and $\mathrm{Pd}_{2} \mathrm{Si}$-TiN-Au. The design of the switching diodes was similar to that of the IMPATT diodes. The parameters of the switching diodes are given in Table 3.

The series resistance of diodes at a frequency of 10 $\mathrm{GHz}$ (the forward current being $10 \mathrm{~mA}$ ) was below $1.0 \Omega$. When switching from the forward current of $10 \mathrm{~mA}$ to the reverse voltage of $10 \mathrm{~V}$, the reverse resistance recovery time was 3-10 ns. In the millimeter wavelength range the diodes provided transmission losses 0.7 to $1.0 \mathrm{~dB}$, blocking losses over $30 \mathrm{~dB}$ and the microwave signal switching time from 1 to $3 \mathrm{~ns}$.
The fast-operating switching diodes practically are not overheated during operation. The reasons for their parameters degradation may be short-term electrical overloads. Simulation of the operation modes at elevated $\left(135^{\circ} \mathrm{C}\right)$ package temperatures demonstrated high stability of the diode parameters. Exposition to ${ }^{60} \mathrm{Co} \gamma$-radiation (total doses up to $10^{8} \mathrm{R}$ ) results in a decrease of the stored charge and reverse current. It also leads to stabilization of the I-V curves in the avalanche breakdown mode.

\section{Varactor diodes}

The varactor diodes with bulk contacts were fabricated according to the technological route presented in Fig. 3. The technological procedures and fabrication stages are as follows: $1-p^{+}$-layer formation using precise boron diffusion to a silicon $n-n^{+}$-structure (60 $\mathrm{mm}$ in diameter); 2 - membrane $(10 \pm 2 \mu \mathrm{m}$ thick and $45 \mathrm{~mm}$ in diameter) etching on the $n^{+}$-layer side; 3 - sputtering of $\mathrm{Pd}_{2} \mathrm{Si}$-Ti-

Table 3. Fast-operating switching diodes (continuous operation mode)

( $U_{R}$ - reverse voltage, $I_{F}$ - forward current).

\begin{tabular}{|c|c|c|c|c|}
\hline Operation frequency, $\mathrm{GHz}$ & $33-37$ & $38-78$ & $92-96$ & $120-140$ \\
\hline Diode capacitance $\left(U_{R}=10 \mathrm{~V}\right), \mathrm{pF}$ & $0.3-0.4$ & $0.25-0.35$ & $0.12-0.15$ & $0.1-0.13$ \\
\hline $\begin{array}{l}\text { Time of microwave power } \\
\text { switching, ns }\end{array}$ & $1-3$ & $1-3$ & $5-10$ & $5-10$ \\
\hline $\begin{array}{l}\text { Forward loss resistance } \\
\left(I_{F}=10 \mathrm{~mA}\right), \mathrm{W} \\
\end{array}$ & $1-3$ & $1-3$ & $1-3$ & $1-3$ \\
\hline Breakdown voltage, $\mathrm{V}$ & 40 & 40 & 40 & 40 \\
\hline Operation current, $\mathrm{mA}$ & 10 & 10 & 10 & 10 \\
\hline Package capacitance, $\mathrm{pF}$ & 0.2 & 0.16 & 0.08 & 0.08 \\
\hline Corundum bush sizes, $\mathrm{mm}$ & $1.2 \times 0.7 \times 0.4$ & $0.9 \times 0.55 \times 0.3$ & $0.4 \times 0.2 \times 0.15$ & $0.4 \times 0.2 \times 0.15$ \\
\hline $\begin{array}{l}\text { Limiting continuous microwave } \\
\text { power (at temperatures of } 60-70^{\circ} \mathrm{C} \text { ), }\end{array}$ & 200 & 200 & 200 & 200 \\
\hline
\end{tabular}


N.S. Boltovets et al.: Microwave diodes with contact metallization systems ...
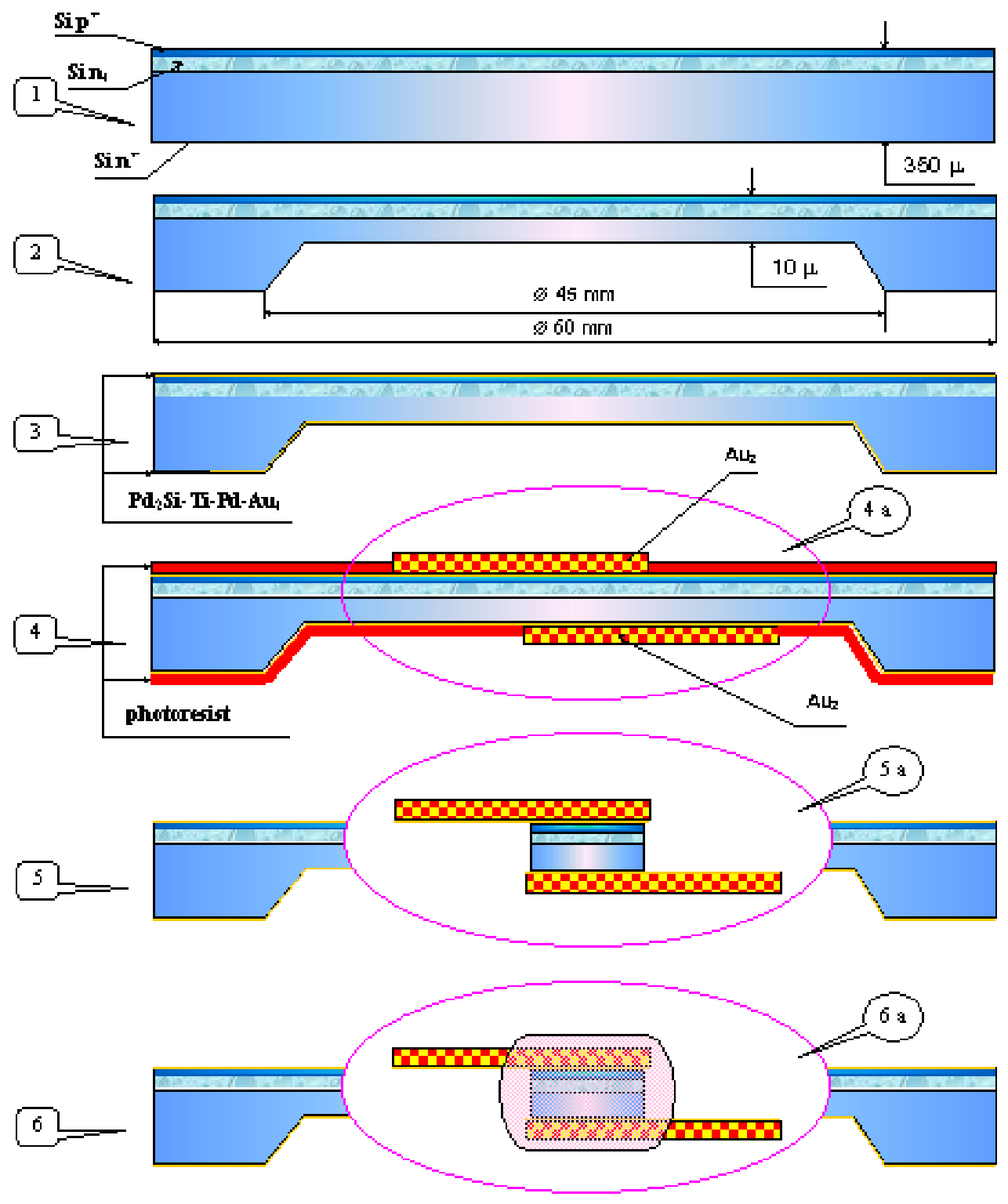

Fig. 3. A diagram of technological route for varactor diodes manufacturing.

$\mathrm{Pd}-\mathrm{Au}$ - or $\mathrm{Pd}_{2} \mathrm{Si}$-Ti-Au-type contact systems to $p^{+}$- and $n^{+}$-regions; 4 - formation of bulk contacts $(6 \div 8 \mu \mathrm{m}$ thick $)$ using local deposition of gold layers; 5 - etching of the deposited metal layers and mesa etching; 6 - protection of mesa surface with a silicone compound. The varactor diode design is shown in Fig. 4.
A special feature of the starting $n-n^{+}$-structure is the doping profile of the $n$-layer (see Fig. 5 where such profiles, $n=f(x)$, are given for two wafers). The corresponding $\mathrm{C}-\mathrm{V}$ curves that provide capacitance span ratio about $10 \div 12$ are shown in Fig. 6 . 
N.S. Boltovets et al.: Microwave diodes with contact metallization systems ...
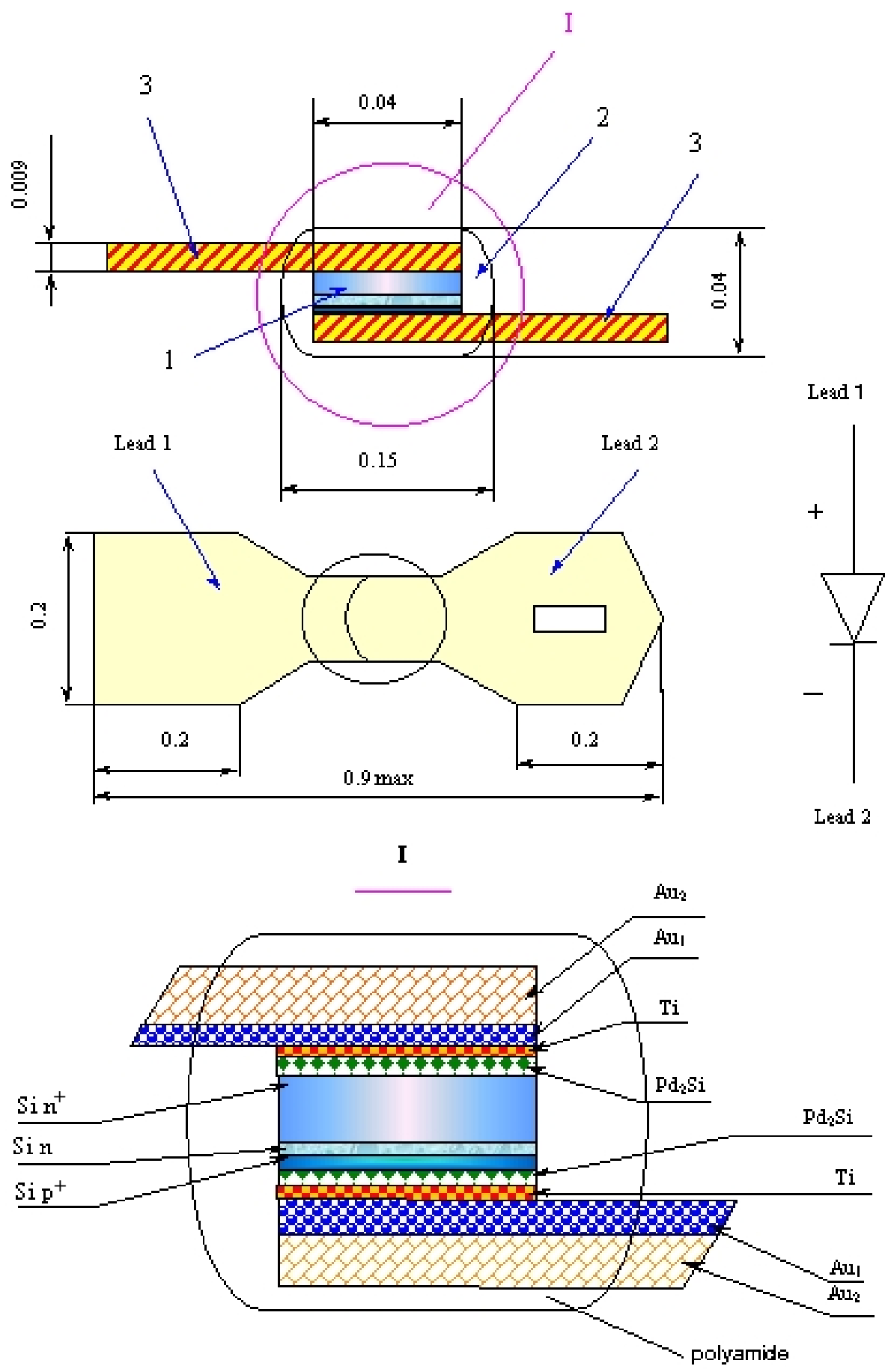

Fig. 4. The varactor diode design: 1 - silicon mesa; 2 - protecting cover; 3 - gold leads. 


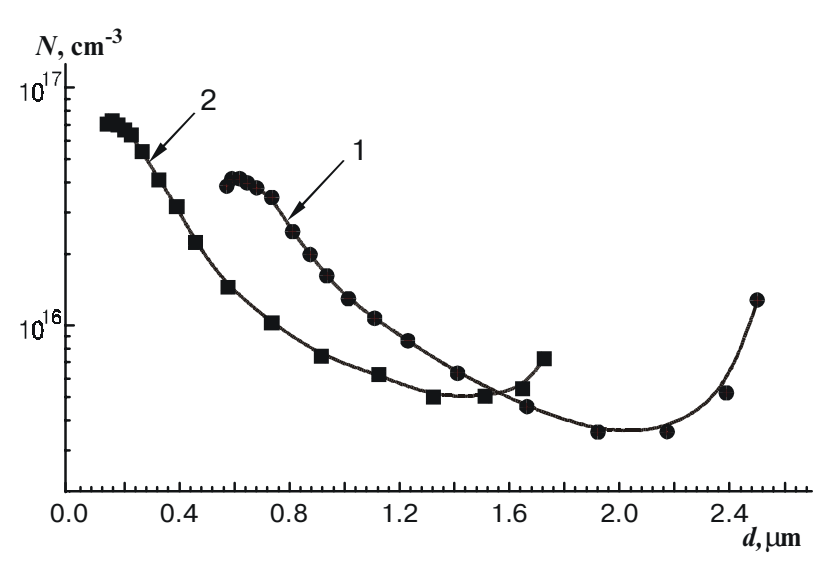

Fig. 5. $n$-doping profiles for two wafers used in varactor diode manufacturing.

\section{Gunn diodes}

The design of a Gunn diode chip was a reversed $M-n-n^{+}$$n^{++}$-type mesa on the gold integrated heat sink (see Fig.7). The gallium arsenide epitaxial structures of the $n-n^{+}-n^{++}$. type were used as the starting material. The Ge-Au-TiB $2^{-}$ Mo-Au contact systems to the $n$ and $n^{++}$regions were prepared by magnetron sputtering followed by fusion in the hydrogen flow. The diode chips were mounted in the soldered metal-corundum packages. The Gunn diode parameters are given in Table 4.

The oscillating Gunn diodes provide output microwave power of $100 \div 60 \mathrm{~mW}$ in the 35 to $60 \mathrm{GHz}$ frequency range and up to $50 \mathrm{~mW}$ in the 60 to $100 \mathrm{GHz}$ frequency range. After the diodes were being kept at a temperature of $400{ }^{\circ} \mathrm{C}$ for $30 \mathrm{~min}$. or exposed to temperature cycling in the 20 to $400{ }^{\circ} \mathrm{C}$ temperature range, their characteristics did not degraded.

The reliability testing was performed for diodes operating in the forced modes at package temperature of $100{ }^{\circ} \mathrm{C}$ for $1000 \mathrm{~h}$. It has demonstrated high stability of the diode parameters during the above testing, as well as during ${ }^{60} \mathrm{Co} \gamma$-irradiation (up to the dose of $10^{7} \mathrm{R}$ ).

Sputtering of AuGe eutectic alloy followed by shortterm heat annealing in a vacuum or reducing atmosphere at a temperature of about $450{ }^{\circ} \mathrm{C}$ is widely used to prepare ohmic contacts to Gunn diodes. However, the toler-

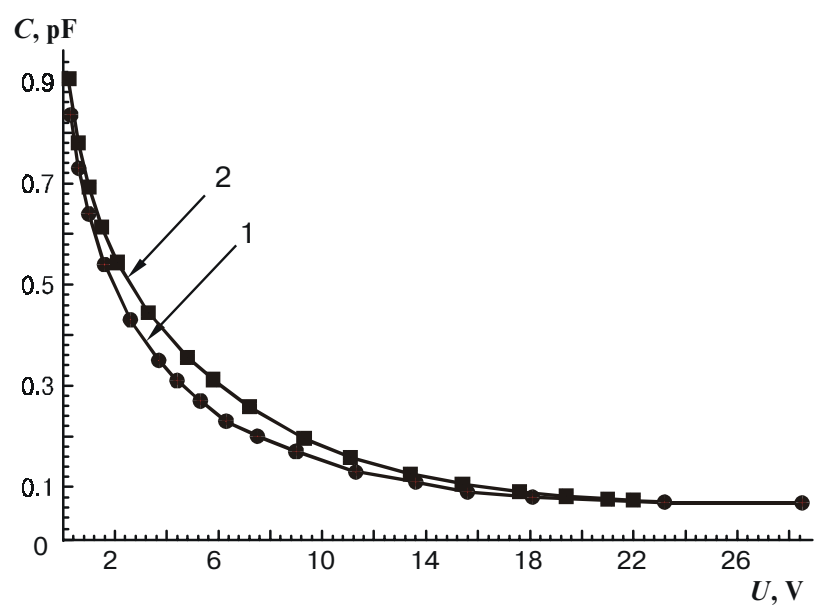

Fig. 6. $C$ - $V$ curves for two wafers used in varactor diode manufacturing.

ance of the resulting contact junction to thermal loads that promote diffusion, phase formation and recrystallization at the interface is not very high. To prevent or hamper the above processes a multilayer metallization containing a titanium-boride-based antidiffusion barrier is often used. The corresponding contact structure is as follows: Au-Mo-TiB ${ }_{x}$-AuGe-GaAs. After fusion at a temperature $430{ }^{\circ} \mathrm{C}$ the prepared contacts demonstrated low resistance and good reproducibility.

We have performed the layer-by-layer Auger analysis of the above systems to investigate the mechanisms of their degradation. It was supplemented with studies of morphology of both film coating and interface.

Shown in Fig. 8 are the concentration depth profiles of the system components taken for initial samples and those annealed at 400, 600 and $800{ }^{\circ} \mathrm{C}$. One can see from these profiles that heat annealing at temperatures below $600{ }^{\circ} \mathrm{C}$ does not lead to a substantial redistribution of the system components and formation of intermetallic compounds at the interface. The type of layered structure begins to change considerably when the samples are annealed at temperatures close to $600{ }^{\circ} \mathrm{C}$. The most pronounced changes occur at the AuGe-GaAs interface. Basing on the results presented in Fig. 8, one may conclude that the reasons for the changes observed are not related to chemical modification of the $\mathrm{TiB}_{x}$ layer. This is evident from the results of morphology investigations

Table 4. Oscillating Gunn diodes (continuous operation mode).

\begin{tabular}{llccccc}
\hline \hline Operation frequency, $\mathrm{GHz}$ & $17-26$ & $26-37.5$ & $37.5-54$ & $53-78$ & $40-78$ & $60-100$ \\
\hline Minimum continuous power, $\mathrm{mW}$ & $25-300$ & $10-100$ & $10-60$ & $10-50$ & $10-50$ & $10-50$ \\
\hline Operation voltage, $\mathrm{V}$ & $5-7$ & $3-5$ & $2.5-4$ & $4-7$ & $4-6$ & $4-5$ \\
\hline Operation current, $\mathrm{A}$ & $0.25-1.2$ & $0.15-1.2$ & $0.15-1.2$ & $0.15-1.2$ & $0.15-1.2$ & $0.25-1.2$ \\
\hline Package capacitance, $\mathrm{pF}$ & 0.3 & 0.2 & 0.2 & 0.2 & 0.2 & 0.2 \\
\hline Package inductance, $\mathrm{nH}$ & 0.2 & 0.2 & 0.1 & 0.1 & 0.1 & 0.1 \\
\hline Corundum bush sizes, $\mathrm{mm}$ & $1.2 \times 0.7 \times 0.4$ & $1.2 \times 0.7 \times 0.4$ & $0.9 \times 0.5 \times 0.3$ & $0.9 \times 0.5 \times 0.3$ & $0.9 \times 0.5 \times 0.3$ & $0.5 \times 0.3 \times 0.3$ \\
\hline \hline
\end{tabular}




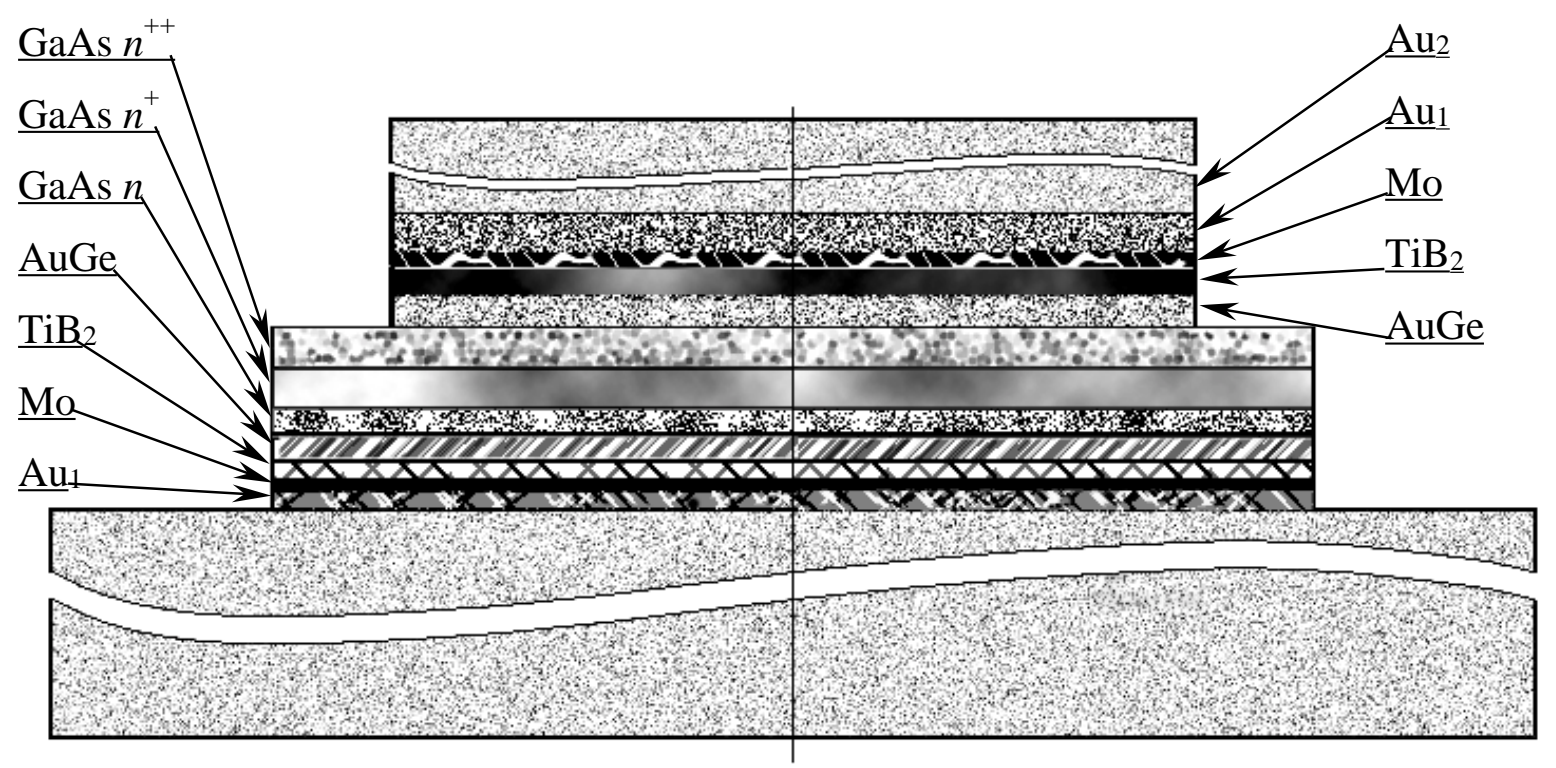

Fig. 7. The Gunn diode chip design.

for the metallization layers that have been performed using atomic force microscopy (Fig. 9). One can see that cracking of the above layers is the principal reason for violation of titanium boride barrier properties during high-temperature annealing. The pores and cracks serve as additional channels for both gold penetration to the interface and semiconductor components cropping out at the metal surface. The first of these processes is favored
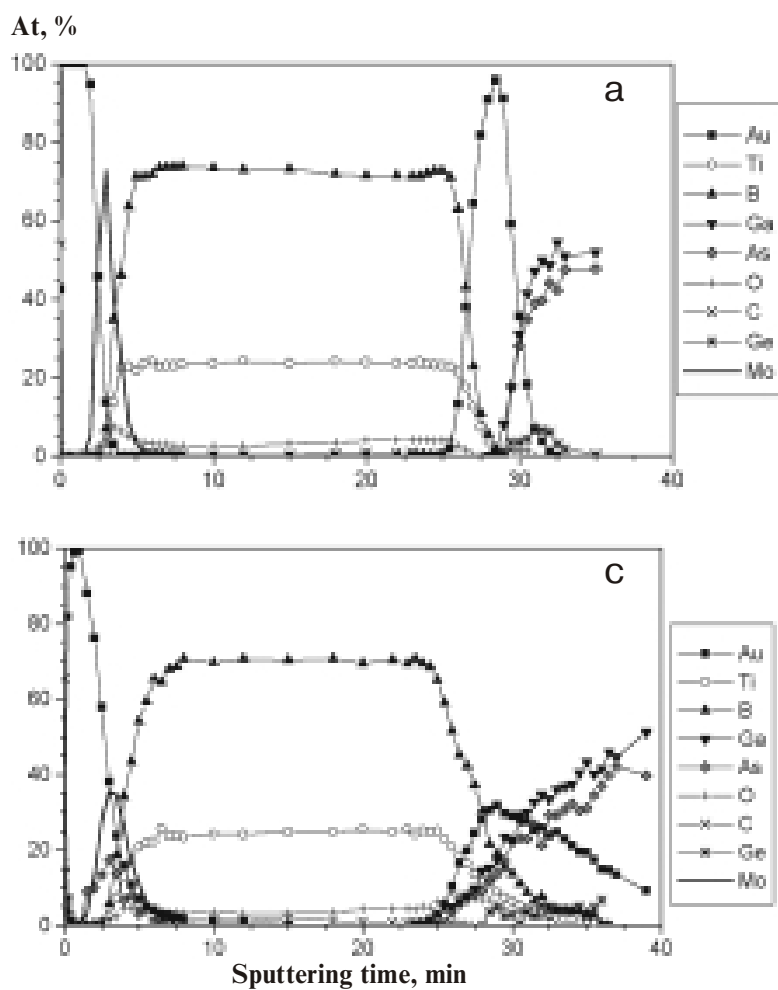

with the loss of barrier properties by Mo layer at $600{ }^{\circ} \mathrm{C}$ (see Fig. 8, while the second one is promoted by GaAs thermal decomposition.

Further contact degradation is related to the liquid phase formation on the GaAs surface. This phase involves gold, germanium, gallium and arsenic, generally with any component ratios. When crystallization from the liquid phase occurs under cooling, then thin polycrystalline
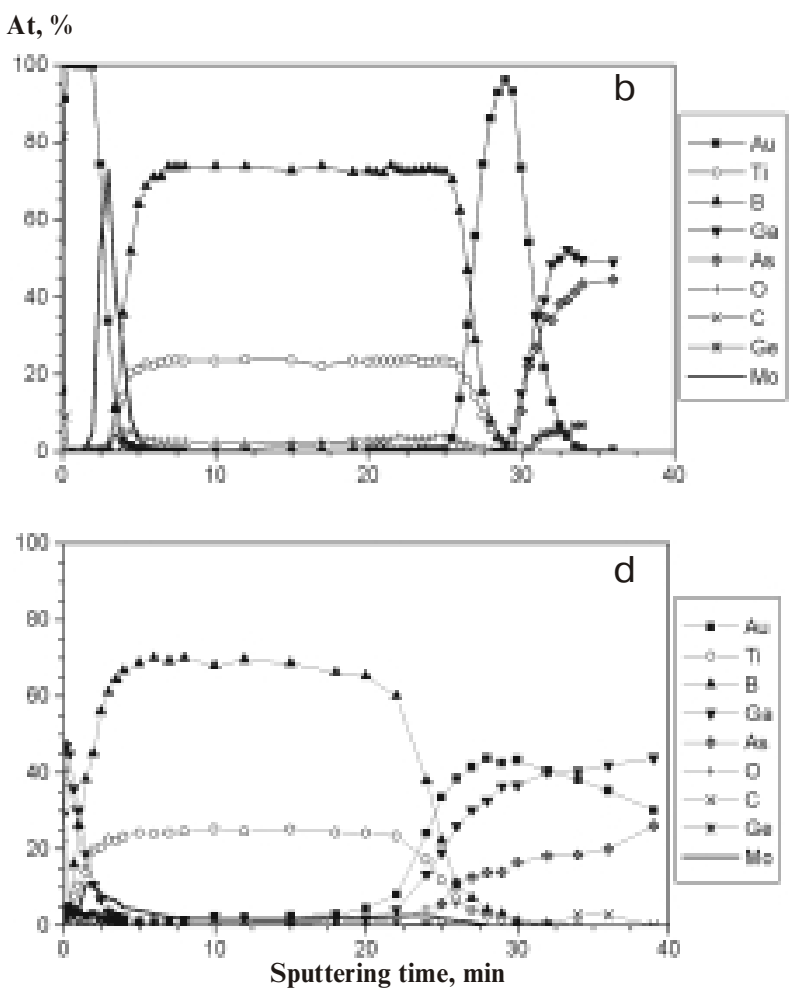

Fig. 8. Auger concentration depth profiles for the $\mathrm{Au}-\mathrm{Mo}-\mathrm{TiB}_{x}-\mathrm{AuGe}-\mathrm{GaAs}$ heterostructure components and $\mathrm{C}$ and $\mathrm{O}$ contaminants. 
N.S. Boltovets et al.: Microwave diodes with contact metallization systems ...
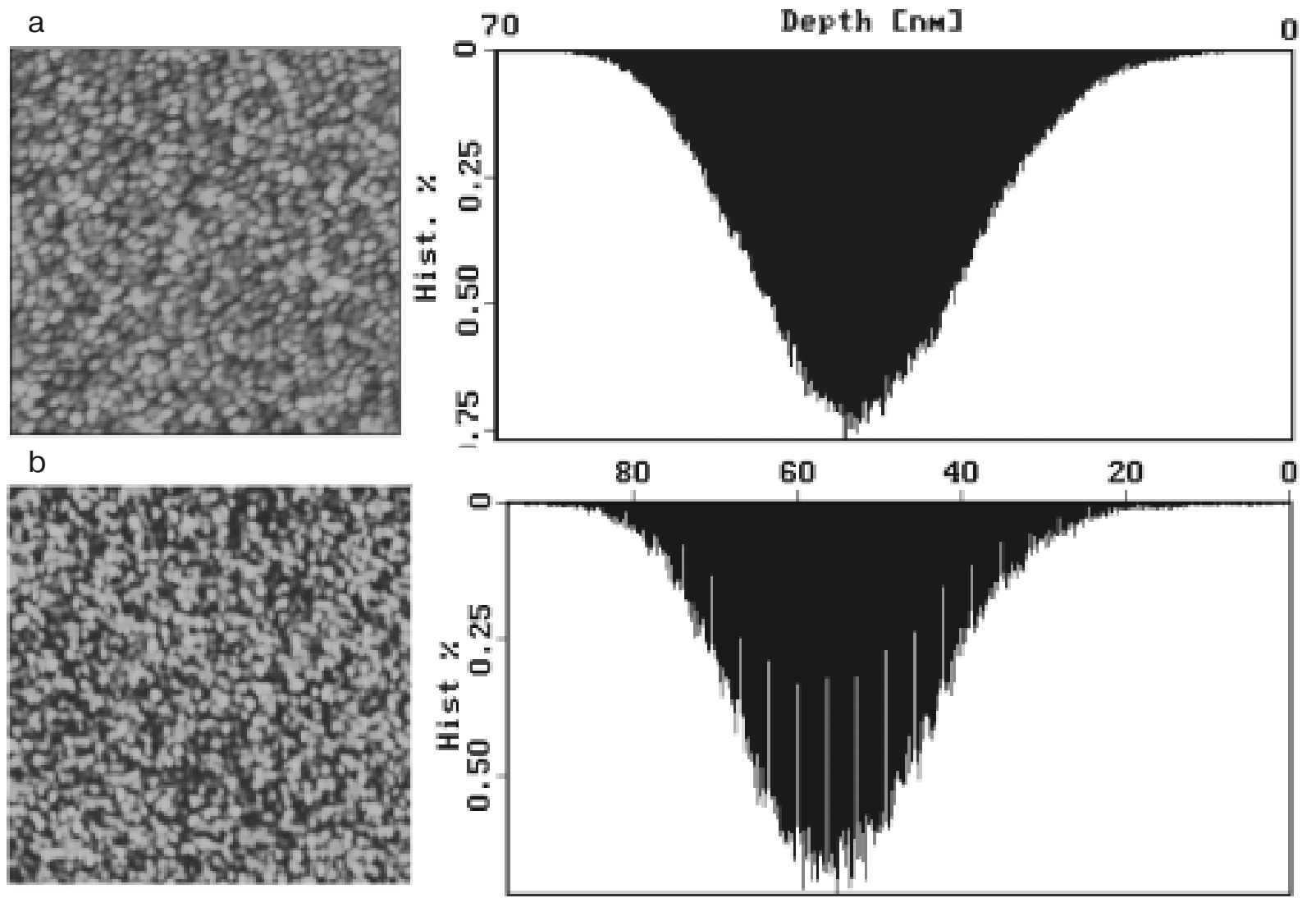

C
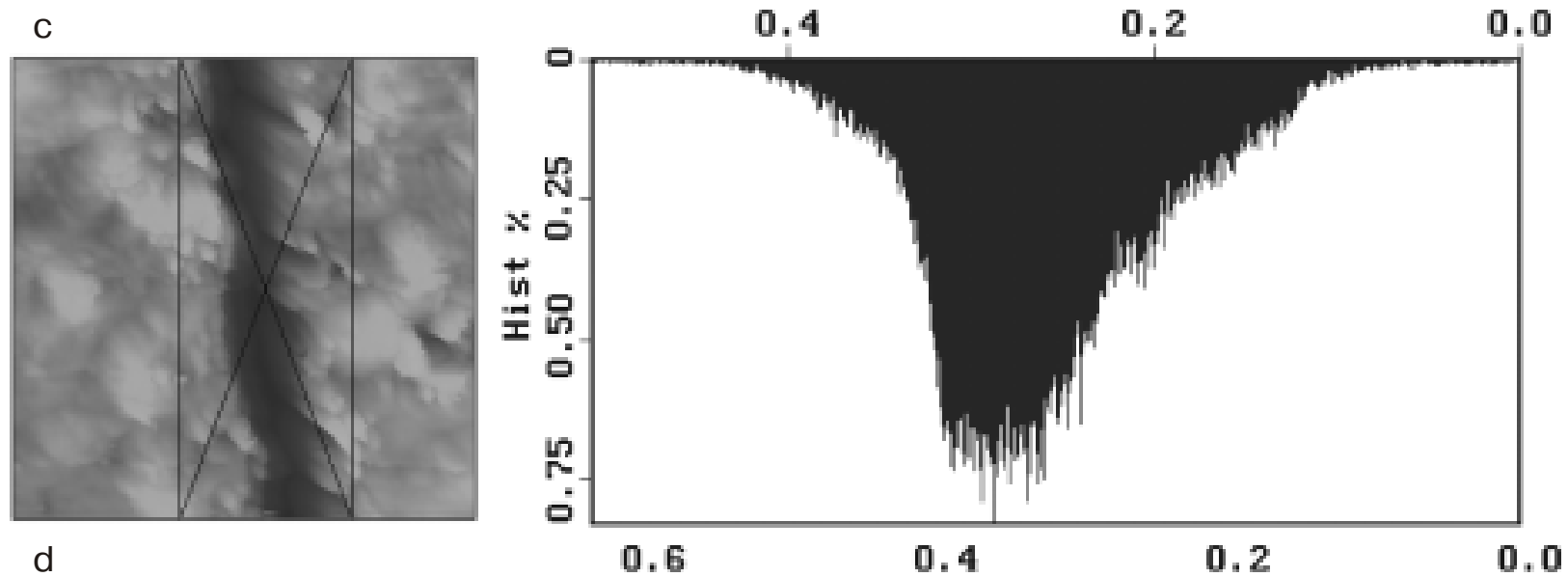

d

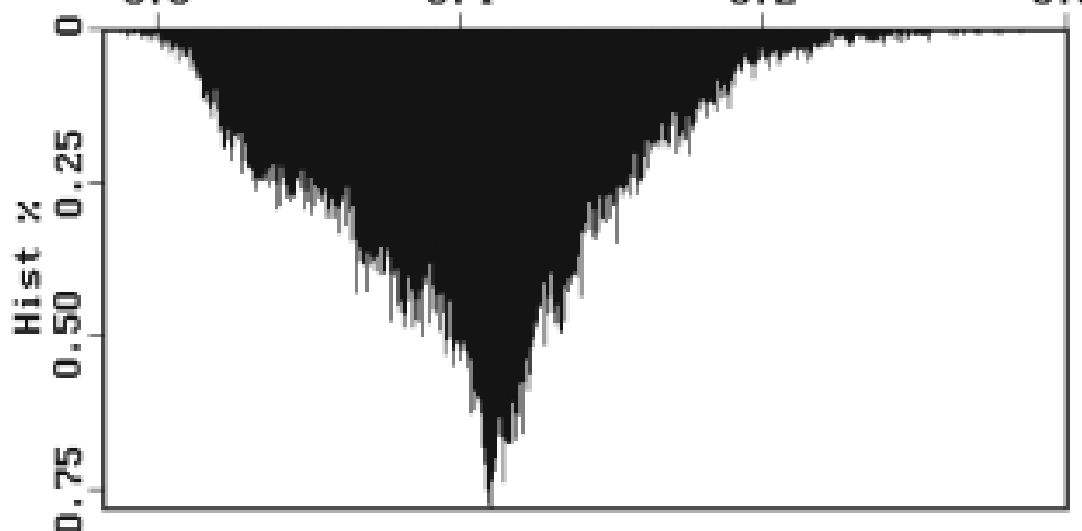

Fig. 9. The Au-Mo-TiB ${ }_{x}$-AuGe-GaAs heterostructure morphology studied with atomic force microscopy. 


\section{N.S. Boltovets et al.: Microwave diodes with contact metallization systems ...}

layers of GaAs (doped with Au and Ge) and gold-gallium alloy appear at the contact interface. Both the order in which the above phases precipitate and degree of their manifestation depend on the amount of gold that diffuses from the upper layer to the interface. This interface, being formed under the above conditions, must be more uniform than that in the initial structure. This is supported by the patterns shown in Fig. 9 .

Presence of strongly compensated recrystallized layer on the GaAs surface leads to the contact resistance increase in the junctions studied.

\section{Microwave oscillating diodes based on the resonant tunneling structure}

The resonant tunneling diodes were fabricated on the basis of GaAs tunnel diodes with a $p$ - $n$ junction (about $10 \mu \mathrm{m}$ in diameter) and two $\delta$-layers built in the space charge region. The interlayer spacing was $5 \mathrm{~nm}$. Concentrations of free charge carriers in the $p^{+}$-layer, $n^{+}$-layer and $\delta$ layers were $\sim 10^{20} \mathrm{~cm}^{-3}, 10^{19} \mathrm{~cm}^{-3}$ and $10^{13} \mathrm{~cm}^{-2}$, respectively.

The diode chips were mounted in the commercial microwave diode packages. At a frequency of $10 \mathrm{GHz}$ the generated power was about $10 \mu \mathrm{W}$. In the same frequency range we also observed microwave generation (power of several $\mu \mathrm{W}$ ) of the resonant tunneling diodes made on the basis of AlAs/GaAs/AlAs heterostructure (the low-frequency parameters of such diodes have been studied in [5]). Our investigations have proved high (up to a dose of $2 \times 10^{9} \mathrm{R}$ ) radiation stability for resonant tunneling diodes of both types [6,7].

\section{Diode temperature sensors}

The fact that the reverse current, forward voltage drop and reverse breakdown voltage of $p-n$ junctions at dc are temperature-dependent is widely used to measure temperature. The temperature dependence of forward voltage drop on $p$ - $n$ junctions is used to convert temperature to an electric signal most often. The reason for this is as follows. First, the forward voltage drop at a constant current through a $p-n$ junction is practically linear in temperature over wide temperature range. (The low-temperature region, $T<100 \mathrm{~K}$, provides an exception.) Second, the forward voltage change with temperature is easily measured for $p-n$ junctions. At present several firms produce special diode temperature sensors based on silicon and gallium arsenide. Such sensors are used, as a rule, to measure temperatures in the 2 to $400 \mathrm{~K}$ range. A review of the state of the art in cryogenic thermometry, in particular, with diode temperature sensors is given in [8].

The principal objective of this work was to develop the Si-based diode temperature microsensors for local temperature measurement in a wide (from 1 to $600 \mathrm{~K}$ ) range. It is known that some specific requirements are imposed upon the package design when producing a device that operates in a wide temperature range (especially at low and ultralow temperatures). Such a design has to provide the required thermal properties, high reliability and stability of device characteristics during repeated cooling and heating cycles (in particular, at fast thermal shocks).

The silicon element for temperature sensors with improved radiation stability is a $p^{+}-n-n^{+}$planar diode (Fig. 10). The diode structure was prepared in the follow-

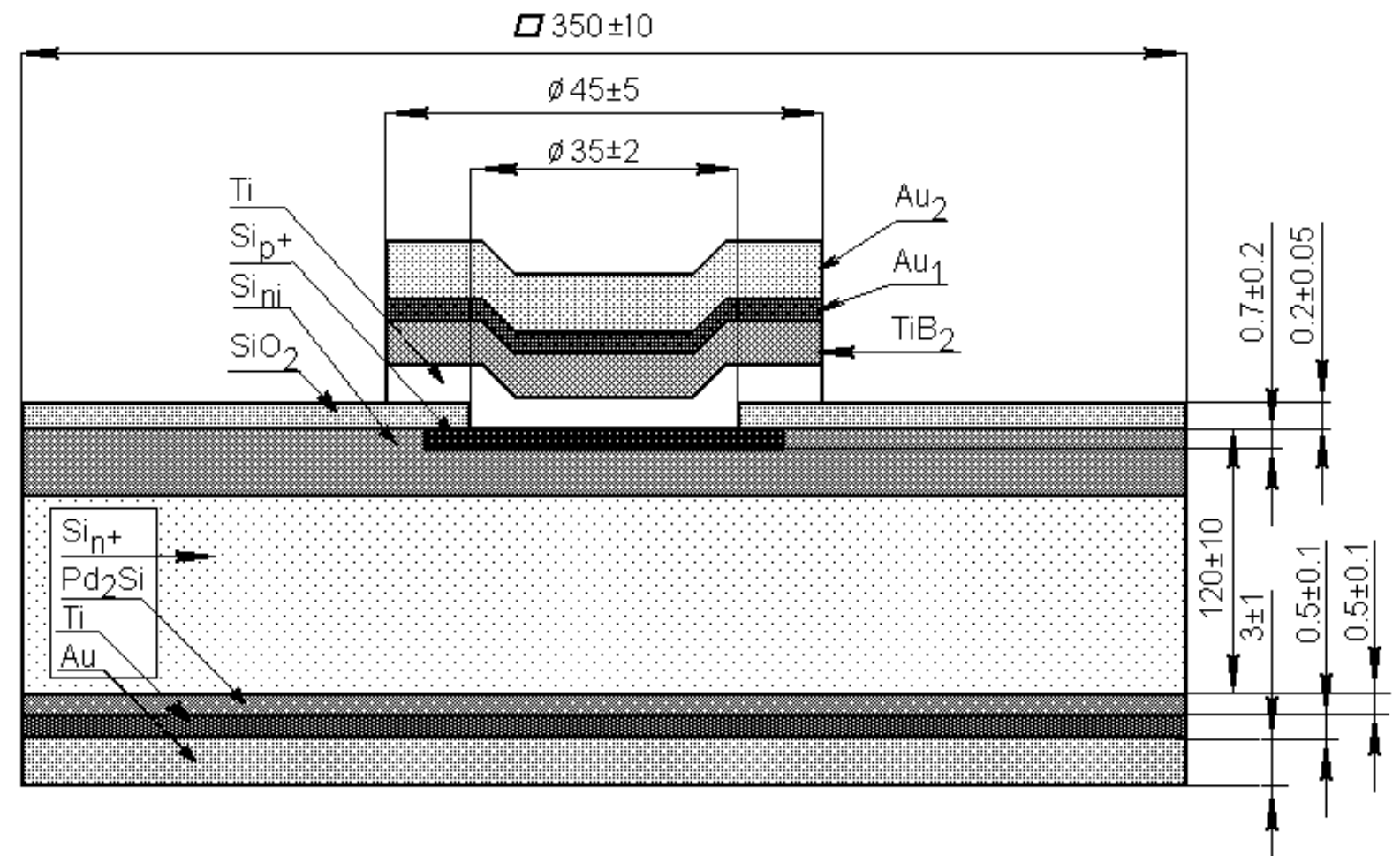

Fig. 10. The design of a silicon element for diode temperature sensors. 


\section{N.S. Boltovets et al.: Microwave diodes with contact metallization systems ...}

ing way. At first silicon epitaxial $n^{+}-n$ structures have been prepared. Resistivity of the epitaxial $n$-layer $(1.5 \mu \mathrm{m}$ thick) was $0.15 \Omega \cdot \mathrm{cm}$. A $\mathrm{SiO}_{2}$ layer $(0.5 \mu \mathrm{m}$ thick $)$ was then formed on the epitaxial $n$-layer, and windows, 100 $\mu \mathrm{m}$ in diameter, were made in this layer. Through these windows boron diffusion to the depth of $0.8 \mu \mathrm{m}$ was performed to make a $p^{+}$-layer. The electric contacts to this $p^{+}$-layer were formed by sequential $\mathrm{Ti}, \mathrm{TiB}_{2}$, and $\mathrm{Au}$ depo- sition using magnetron sputtering followed by electrochemical deposition of gold. The electric contacts to the $n^{+}$-layer were $\mathrm{Pd}_{2} \mathrm{Si}$-Ti-Au structure. The size of the diode structure obtained was $0.35 \times 0.35 \mu \mathrm{m}$. This diode structure was placed in nonmagnetic miniature package.

The package design of diode temperature sensor is shown in Fig. 11. The leads to Si diode structures were formed using thermal compression welding or pulse weld-
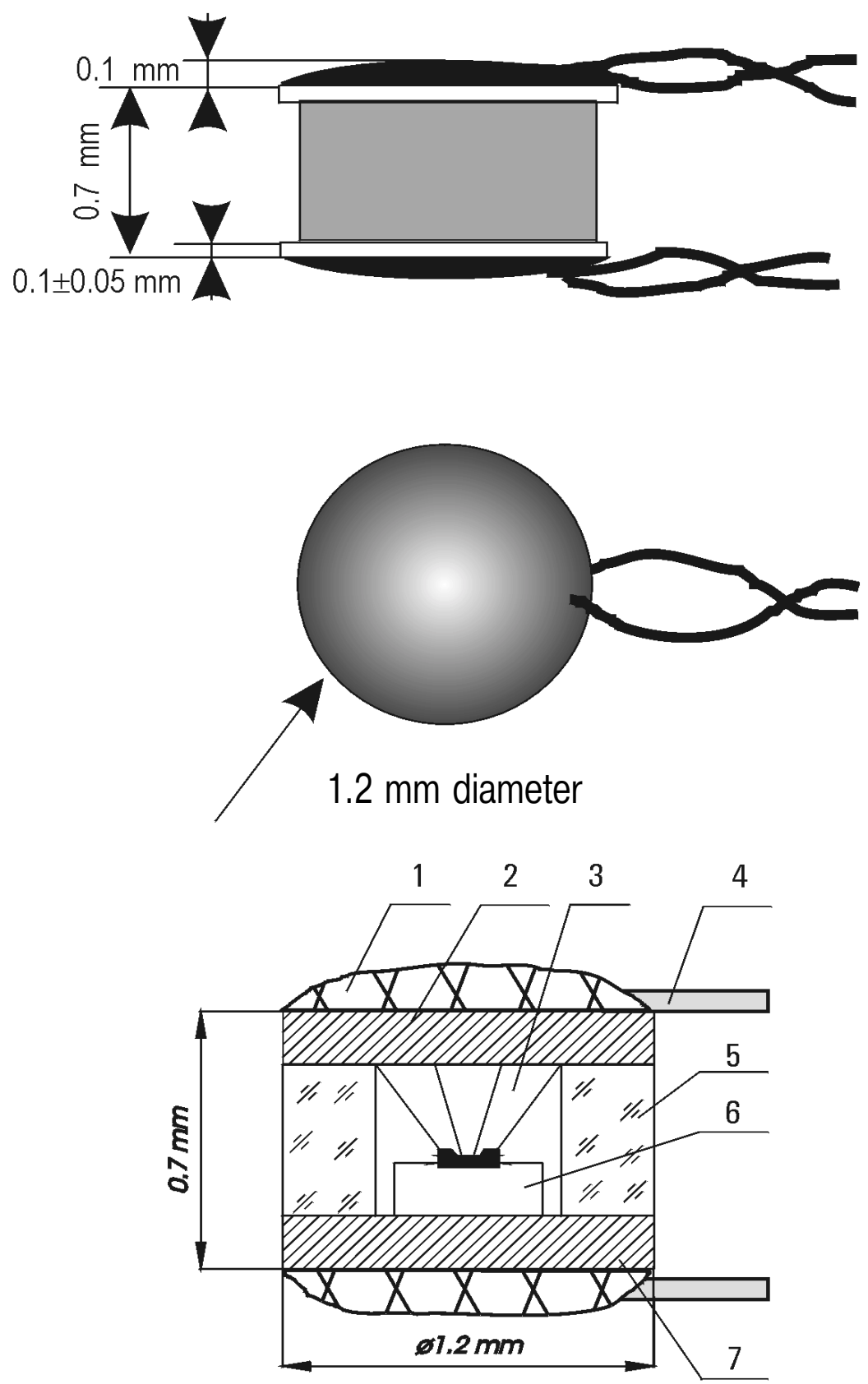

1 - tin; 2 and 7 - copper discs; 3 - leads; 4 - cooper wire; 5 - corundum cylinder; 6 - sensitive element

Fig. 11. Schematic view and package design of a silicon diode for temperature sensors. 

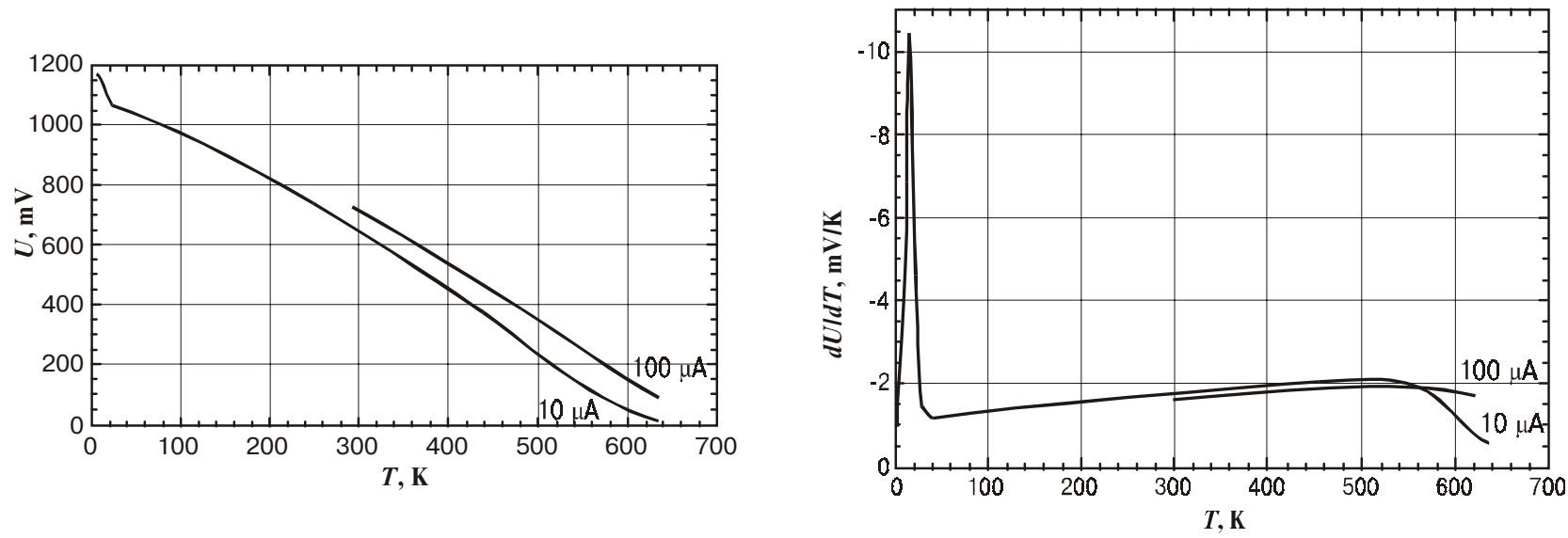

Fig. 12. Voltage $U$ (a) and sensitivity $d U / d T$ (b) vs temperature curves at different currents.

ing of a thin $(6 \mu \mathrm{m})$ gold strip (about $150-200 \mu \mathrm{m}$ wide). The package involved a corundum cylinder and two copper discs covered with a thin Au layer. Similar thin $\mathrm{Au}$ layers were deposited also onto the corundum cylinder ends. The discs were sealed to the corundum cylinder using thermal diffusion welding of Au layers. A sensitive element was placed at one of the copper discs using thermal diffusion welding. Copper wire $(50 \mu \mathrm{m}$ in diameter $)$ was tin-soldered to the copper discs; it served as outer terminals. Taking into account the outer terminals and tin solder thickness values, one can see that the thermometer over-all size was $\varnothing 1.2 \times 1.0 \mathrm{~mm}$. This package protects a sensitive element from harmful external actions and provides very good stability of thermometric characteristics.

Shown in Fig. 12 is the forward voltage, $U$, and sensitivity, $S$, versus temperature curves in the 4.2 to $600 \mathrm{~K}$ temperature range. One can see from the above figures that such diode temperature sensors demonstrate high thermal sensitivity and relatively good linearity of their thermometric characteristics in the 30 to $600 \mathrm{~K}$ temperature range.

\section{Conclusion}

Our investigations have demonstrated that contact systems based on the silicides, borides and nitrides of refractory metals are promising for production of microwave diodes having an improved reliability when operating for a long time at elevated temperatures. The radiation tolerance of these diodes is rather high.

\section{Acknowledgements}

The development of varactor diodes and resonant tunneling diodes, as well as fast-operating switching diodes for the 33-78 GHz frequency range and IMPATT diodes for the 33-37 and 70-77 GHz frequency ranges, was carried out under the INCO-COPERNICUS Program (Project No 977131 "MEMSWAVE").

\section{References}

1. R.V. Konakova, P. Kordos, Yu.A. Tkhorik et al., Reliability Prediction for the Semiconductor Avalanche Diodes (in Russian), Naukova Dumka, Kiev (1986).

2. M. Shur, GaAs Devices and Circuits, Plenum Press, New YorkLondon (1987).

3. V.A. Makara, N.S. Boltovets, V.A. Pasechny, O.V. Rudenko, Barrier properties of different multilayer metallization systems, in: Proc. Intern. Metallography Conf. MC'95, 10-12 May 1995, Colmar, France, pp. 423-428.

4. R.V. Konakova, N.A. Prima, E.A. Soloviev, Simulation of thermal instabilities in the active microwave elements (in Russian), in Proc. 8th Intern. Crimean Conf. "Microwave Devices and Telecommunication Technologies", 14-17 September 1998, 1, pp. 392-395, Weber Publ., Sevastopol (1998).

5. N.A. Prima, E.A. Soloviev, N.S. Boltovets, On a model of disastrous failures in oscillating microwave diodes (in Russian), in Proc. 9th Intern. Crimean Conf. "Microwave Devices and Telecommunication Technologies", 13-16 September 1999, pp. 87-88, Weber Publ., Sevastopol (1999).

6. A.E. Belyaev, R.V. Konakova, E.A. Soloviev, E.F. Venger, S.A. Vitusevich, Yu.A. Tkhorik, I.Yu. Il'in, Enhanced radiation hardness of tunneling diodes with delta-doping, in Proc. Intern. Workshop "3rd Bratislava Days on Molecular Beam Epitaxy”, May 16-17, 1996, Eds. R. Redhammer, M. Bujdák, D. Papajová, pp. 90-93, STU, Bratislava (1996).

7. A.A. Belyaev, A.E. Belyaev, R.V. Konakova, S.A. Vitusevich, V.V. Milenin, E.A. Soloviev, L.N. Kravchenko, T. Figielski, T. Wosinski, A. Makosa, Radiation hardness of AlAs/GaAsbased resonant tunneling diodes // Semiconductor Physics, Quantum Electronics \& Optoelectronics 2(1), pp. 98-101 (1999).

8. L.G. Rubin, Cryogenic thermometry: a review of progress since 1982 // Cryogenics 37(7), pp. 341-356 (1997). 